\title{
Effects of modified atmosphere storage on banana postharvest diseases and the control of bunch main-stalk rot
}

\author{
N.L. Wade ${ }^{\text {a }}$, E.E. Kavanagh ${ }^{\mathrm{b}}$ and M. Sepiah ${ }^{\mathrm{c}}$ \\ ${ }^{a}$ NSW Agriculture located at CSIRO Food Research Laboratory, North Ryde, NSW, Australia \\ ${ }^{b}$ CSIRO Food Research Laboratory, North Ryde, NSW, Australia ' Division of Basic Research, MARDI, \\ Serdang, Kuala Lumpur, Malaysia
}

(Accepted 20 April 1993)

\begin{abstract}
Banana (Musa, AAA) bunch-sections consisting of one hand attached to a short section of main-stalk were wound-inoculated with cultures of fungi isolated from diseased fingers, crowns, or main-stalks and stored in sealed polyethylene bags containing 3-7\% oxygen, 10-13\% carbon dioxide and $<0.1 \mu \mathrm{l}^{-1}$ ethylene for 40 days at $20^{\circ} \mathrm{C}$, then ripened with ethylene in air for nine days. Colletotrichum musae, Fusarium moniliforme var. subglutinans and Nattrassia mangiferae caused high infection incidence in unripe fingers during storage. These fungi also caused crown rot, but only $F$. moniliforme var. subglutinans caused main-stalk rot. Alternaria alternata and $F$. pallidoroseum both caused some infection in unripe fingers during storage, and both subsequently caused crown rot. $A$. alternata also infected main-stalks. Lasiodiplodia theobromae and Phomopsis musicola infected only ripening fingers, and $F$. culmorum infected only crowns and main-stalks. The pathogenicity of some isolates was changed by interposing storage between inoculation and ripening. $C$. acutatum and $C$. gloeosporioides became unable to cause disease and $F$. culmorum caused less disease. In contrast, $A$. alternata and $F$. pallidoroseum became pathogenic to fingers, crowns and, in the case of $A$. alternata, to bunch main-stalks. Benomyl and prochloraz $\left(500 \mathrm{mg} \mathrm{l}^{-1}\right)$ controlled most diseases at inoculation sites, and naturally-occurring main-stalk rot. Prochloraz controlled more diseases than benomyl, and this control was usually more effective.
\end{abstract}

Key words: Banana; Musa; Rot, finger, stalk, crown, bunch main-stalk; Benomyl; Prochloraz

\section{INTRODUCTION}

Modified atmosphere (MA) storage of bananas is a versatile technology applicable to a wide range of cultivars, including $\mathrm{AA}, \mathrm{AAA}, \mathrm{AAB}$ and $\mathrm{ABB}$ or $\mathrm{BBB}$

Correspondence to: N. Wade, NSW Agriculture, Horticultural Research \& Advisory Station, PO Box 581, Gosford, NSW, 2250, Australia. 